\title{
An Empirical Research of Successful ERP Implementation Based on TAM
}

\author{
Dong Cheng, Dehong Yang, Jidong Han and Yuanfang Song \\ School of Business, Renmin University of China, Beijing 100872, P. R. China \\ chengdong@ruc.edu.cn dehong.yang@wincor-nixdorf.com hjdruc@gmail.com, \\ rucsongyuanfang@yahoo.com.cn
}

\begin{abstract}
The issues of enterprise resource planning (ERP) implementation have been given much attention due to its high failure rate. Some researches were focused on the influence of perceived use (PU) and perceived ease of use (PEU) on attitude and symbolic adoption based on the theory of technology acceptance model (TAM). Others studied the critical success factors from organizational or personal aspects. However, few scholars put them together to examine the influence of critical success factors on PU and PEU, which are key factors to user acceptance to ERP system. This study develops an integrative framework that links leadership's support, training abilities, change management abilities, business processing abilities and learning abilities with PU and PEU. The present structural equation model encompasses these relationships on the basis of a survey of 340 managers and end-users. This paper highlights two main results. First, leadership's support and training abilities have significant impacts on organizational business processing abilities. Second, change management abilities, business processing abilities and learning abilities, have significant impacts on user perceived ease of use. These findings will help managers to understand that user's perceived ease of use should be considered on organizational level in the construction and implementation of an ERP system.
\end{abstract}

Keywords: Enterprise resource planning (ERP), Enterprise management, Enterprise information systems, Enterprise systems organizational issues, Human resource management, Business process reengineering, Technology acceptance model, Critical success factors

\section{INTRODUCTION}

The enterprise resource planning (ERP) systems were introduced to enterprise mainly for improving information share and communication at first. Some researchers tried to find out what influences the acceptance of information system like ERP. They treat ERP as a new information technology. The technology acceptance model (TAM) was introduced as the fundamental model. A lot of variables were studied to test their impacts on user perceived use (PU) and perceived ease of use (PEU). Other researches were concentrated on the critical success factors. They try to find out some critical success factors to predict the adoption and implementation effectiveness of ERP systems. There are more than twenty factors identified. But how these factors 
influence the adoption and implementation effectiveness is still unknown. They may have direct impact on adoption or they may influence adoption through other variables like PU or PEU. Some critical success factors may be mediate. This study tried to find out the impacts of some critical success factors on PU and PEU of TAM. An integrative framework was developed which links leadership's support (LD), training abilities (TR), change management abilities (CM), business processing abilities (CM) and learning abilities (LG) with PU and PEU. The present structural equation model encompasses these relationships on the basis of a survey of 340 managers and end-users. The paper highlights two main results. First, LD and TR have significant impacts on organizational BP. Second, CM, BP and LG have significant impacts on PEU. These findings will help the manager to understand that user's perceived ease of use should be considered on organizational level in the construction and implementation of an ERP system.

\section{LITERATURE REVIEW}

The proposed framework in this research is based on researches in several fields, which concern technology acceptance, diffusion of innovation and critical success factors. These literatures which provided the necessary theoretical foundations in this study were briefly discussed in the following sections.

\subsection{Researches on the Technology Acceptance}

User attitude and behavioral intention have received much attention in literatures. Several models were developed from the aspect of social psychology: the theory of reasoned action (TRA) was proposed by Fishbein et al. [1] and Ajzen et al. [2]; the theory of planned behavior (TPB) was proposed by Ajzen [3, 4]; the technology acceptance model (TAM) was proposed by Davis [5]. TPB was an extension of TRA by taking into account of the effects of a use's volitional control on behavioral intention. TAM focuses on user acceptance of new technology. The PU, PEU and AT are three main aspects of TAM. They are the key determinants of user intentions. In parsimonious TAM [6], the attitude which was treated as a mediating variable was excluded.

In the implementation of ERP system, the adoption of ERP package is mandatory in most cases. Thus, a new variable was needed to substitute for behavioral intention to examine users' acceptance. Some researches $[7,8]$ proposed a new construct called symbolic adoption, which refers to one's mental acceptance to a new technology.

\subsection{Researches on Diffusion of Innovation}

Diffusion of innovation (DOI) is a similar model to TAM. Tornatzky et al. [9] reported the relationship between innovation characteristics, relative advantage, complexity and compatibility with adoption behavior. Relative advantage was found 
similar to the notion of usefulness and complexity similar to ease of use [5]. In this research, we use TAM as our primary model.

\subsection{Researches on Critical Success Factors}

The concept of critical success factors has been well established in the information system literatures. While the implementations of ERP differ from traditional information systems in many aspects such as scale, complexity, business changes, etc., a more suitable theoretical frame or variables need to be developed for a successful ERP implementation.

Holland et al. [10] proposed a framework for understanding success and failure in ERP implementation. In that research, the critical success factors were divided into the strategic and tactical headings. Based on literature review, Nah et al. [11] identified $11 \mathrm{key}$ critical factors for successful ERP implementation. Somers et al. [12] proposed a comprehensive list of 22 critical success factors through an extensive review of the literature. Based on these three researches, a lot of studies were conducted from different aspects [13-20]. Most of these researches were trying to find out the relationship between critical success factors and implementation effectiveness.

\section{MODEL AND HYPOTHESES}

In this study, TAM is proposed as the fundamental model using symbolic adoption which substitutes for the traditional behavior intention. Therefore, it is hypothesized that:

H1: PEU will have a positive effect on PU.

H2: PEU will have a positive effect on AT.

H3: PU will have a positive effect on AT.

H4: AT will have a positive effect on SA.

H5: PEU will have a positive effect on SA.

H6: PU will have a positive effect on SA.

Altogether 11 to 22 critical success factors were proposed in literatures to explore their impacts on user acceptance or implementation effectiveness. Some critical success factors work on organizational level or personal level both. Others only work on personal level.

The learning ability (LG) refers to activities a company taken to identify cuttingedge ERP technique and pilot-test new methods of using capabilities of ERP system [21]. These organizational activities will improve the use of ERP on personal level. User perceived ease of use of ERP system may by improved through constant learning and pilot-testing of new way of using. Therefore, it is hypothesized that:

H7: LG will have a positive effect on PEU.

The business process ability (BP) refers to a clear process definition and strict compliance with the process. In most case, ERP packages were built around best practices in specific industries, they may not fit the practices of a special corporation. A company needs to customize the package or change its business process [22]. BP 
will help employees to understand how the business operates and predict the impact of a particular action on the rest of the enterprise [23]. The business process of an enterprise will influence the fluency of user's work and then his perceived ease of use of an ERP system. Therefore, it is hypothesized that:

H8: BP will have a positive effect on PEU.

No matter how detailed the package or reengineering business process is customized, the work style of employees may change more or less. The change management ability (CM) refers to the managerial efforts which could help employees to adapt to or lower their worry of new process after implementation of ERP. These efforts will ease user attitude to change. Employees who have positive attitude to organizational change trend to believe that using new information system will help them attain gains in job performance. They believe that the system will give benefits to individuals and organization. User involvement in the design of a new information system may improve his attitude toward change [24]. The impacts of attitude to change on PU and PEU were reported [25]. Therefore, it is hypothesized that:

H9: CM will have a positive effect on $\mathrm{PU}$.

H10: CM will have a positive effect on PEU.

The impacts of the degree of resistance to change from users across the organization on degree of BPR execution were reported [26]. An adequate change management can help employees understand how to adapt to their new duties. Members in organization will benefit from this to understand how the business operates and predict the impact of their own work on organizational goal. Therefore, it is hypothesized that:

H11: CM will have a positive effect on BP

Training ability (TR) refers to activities a company taken to teach general ERP concepts or hands-on operational skills. It included the need specification, preparation of material and training execution. All these require an overall consideration from organizational and business level. Therefore, it is hypothesized that:

H12: CM will have a positive effect on TR.

Training could help employees to understand how ERP affects the work of individuals, how to deal with conflicts created in implementation and how to adjust individual working process etc. Members in organization will benefit from this to understand and strictly comply with the process after the implementation. Therefore, it is hypothesized that:

H13: TR will have a positive effect on BP.

Since ERP implementation includes technological, operational, managerial components from strategic and organizational aspects, ERP may differ from other information technology or information system [27]. ERP is an enterprise-wide, crossfunctional implementation. Both business process re-engineering and change management are beyond the scope of middle level manager and need to be promoted in the whole organization $[13,14]$. The champion of ERP from leadership (LD) may minimize user resistance to change and hence improve the adoption through the whole organization [22]. Therefore, it is hypothesized that:

H14: LD will have a positive effect on CM.

H15: LD will have a positive effect on BP.

H16: $L D$ will have a positive effect on SA. 
The model we proposed is demonstrated in Figure 1.

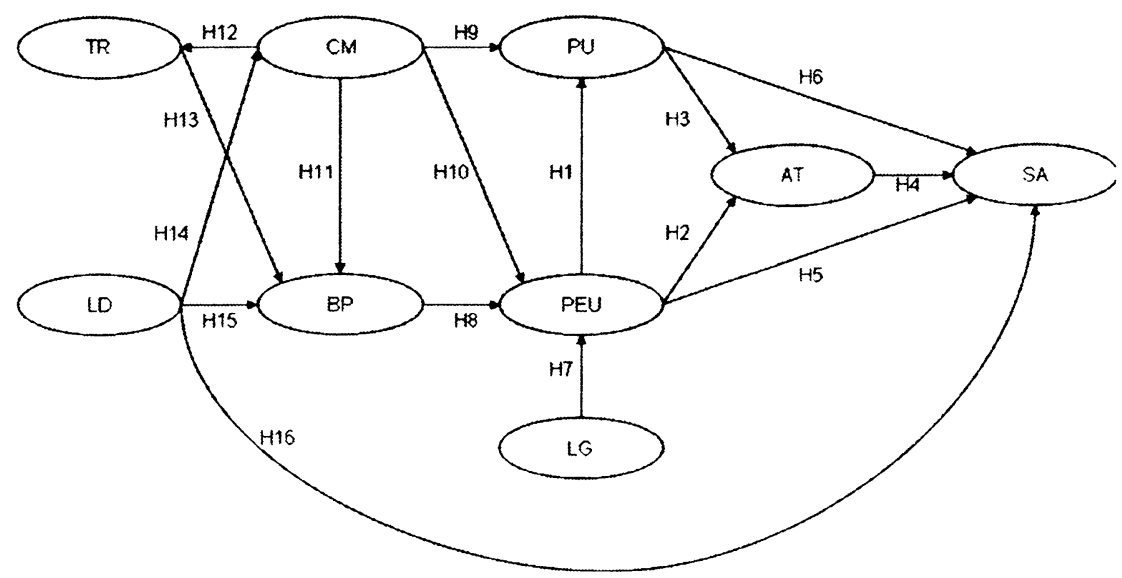

Figure 1. Proposed Structure Model

\section{RESEARCH METHOD}

Data were collected though questionnaires to test the hypotheses. The sample for this study consisted of ERP manager and users in more than thirty organizations. After five months, we obtained valid 340 answers out of 420 feedback questionnaires. The questionnaire items used a 5-point Likert-type scale. Each of these measures contained subscales ranging from 2 to 7 items.

A scale is thought to have content validity if the scale's items form a representative sample in the theoretical domain of the construct $[28,29]$. In this study, we use the usual method of ensuring content validity which is extensive review of literatures. To ensure the content validity of the scale, items used in this study were mostly adopted and modified from previous studies which had been tested.

The most common method to measure the reliability of Likert scales is Cronbach's alpha. Normally, Cronbach's alpha more than 0.6 could be accepted. Cronbach's alpha within the range from 0.7 to 0.9 means high level of reliability. Cronbach's alpha and regression coefficient $\left(\mathrm{R}^{2}\right)$ were used to test the reliability and validity of the measures. Cronbach's alpha of all the variables in this research all stay above the level of acceptance. The measurement model was evaluated by completely standardized factor loadings and $t$-values. The values are showed in Table 1. 


\section{RESULTS}

The data were analyzed using the LISREL structural equation modeling program (LISREL 8.72). To determine model quality, multiple gauges of goodness of fit were used. Absolute, incremental and parsimony fit indices [30] of the proposed model were reported in Table 2, 3, 4 .

Table 5. Related Statistical Values of Factors and Scales

\begin{tabular}{|c|c|c|c|c|c|}
\hline Factor & Indicator & $\begin{array}{c}\text { Completely } \\
\text { Standard } \\
\text { factor loading }\end{array}$ & T-value & $\mathbf{R}^{2}$ & Cronbach's $\alpha$ \\
\hline \multirow{7}{*}{ BP } & BP1 & 0.721 & & 0.519 & 0.862 \\
\hline & BP2 & 0.717 & 12.675 & 0.514 & 0.863 \\
\hline & BP3 & 0.696 & 12.297 & 0.484 & 0.867 \\
\hline & BP4 & 0.768 & 13.580 & 0.590 & 0.858 \\
\hline & BP5 & 0.678 & 11.991 & 0.460 & 0.867 \\
\hline & BP6 & 0.723 & 12.787 & 0.523 & 0.862 \\
\hline & BP7 & 0.703 & 12.436 & 0.495 & 0.867 \\
\hline \multirow{7}{*}{ TR } & TR1 & 0.667 & & 0.444 & 0.870 \\
\hline & TR2 & 0.751 & 12.204 & 0.565 & 0.860 \\
\hline & TR3 & 0.819 & 13.100 & 0.672 & 0.852 \\
\hline & TR4 & 0.792 & 12.752 & 0.628 & 0.854 \\
\hline & TR5 & 0.706 & 11.573 & 0.498 & 0.862 \\
\hline & TR6 & 0.636 & 10.559 & 0.404 & 0.872 \\
\hline & TR7 & 0.665 & 10.987 & 0.442 & 0.869 \\
\hline \multirow{6}{*}{$\mathrm{CM}$} & CM1 & 0.856 & & 0.732 & 0.848 \\
\hline & CM2 & 0.808 & 18.165 & 0.653 & 0.855 \\
\hline & CM3 & 0.674 & 13.948 & 0.454 & 0.869 \\
\hline & CM4 & 0.685 & 14.249 & 0.469 & 0.866 \\
\hline & CM5 & 0.649 & 13.248 & 0.421 & 0.867 \\
\hline & CM6 & 0.775 & 17.020 & 0.600 & 0.848 \\
\hline \multirow{3}{*}{ PU } & PU1 & 0.876 & & 0.768 & 0.892 \\
\hline & PU2 & 0.906 & 23.430 & 0.821 & 0.864 \\
\hline & PU3 & 0.882 & 22.364 & 0.778 & 0.892 \\
\hline \multirow{3}{*}{ PEU } & PEU1 & 0.818 & & 0.670 & 0.822 \\
\hline & PEU2 & 0.791 & 16.114 & 0.625 & 0.845 \\
\hline & PEU3 & 0.872 & 18.052 & 0.760 & 0.776 \\
\hline \multirow{2}{*}{ AT } & AT1 & 0.937 & & 0.878 & \\
\hline & AT2 & 0.919 & 29.073 & 0.844 & \\
\hline \multirow{2}{*}{ SA } & SA1 & 0.866 & & 0.749 & \\
\hline & SA2 & 0.564 & 11.476 & 0.318 & \\
\hline \multirow{5}{*}{ LD } & LD1 & 0.705 & 14.269 & 0.496 & 0.824 \\
\hline & LD2 & 0.778 & 16.383 & 0.606 & 0.814 \\
\hline & LD3 & 0.684 & 13.723 & 0.468 & 0.832 \\
\hline & LD4 & 0.731 & 15.010 & 0.535 & 0.820 \\
\hline & LD5 & 0.721 & 14.723 & 0.520 & 0.814 \\
\hline LG & LG1 & 0.709 & 14.138 & 0.502 & 0.825 \\
\hline
\end{tabular}




\begin{tabular}{|c|c|c|c|c|c|}
\hline \multirow{2}{*}{ Factor } & Indicator & $\begin{array}{c}\text { Completely } \\
\text { Standard } \\
\text { factor loading }\end{array}$ & T-value & $\mathbf{R}^{2}$ & Cronbach's $\alpha$ \\
\hline & LG2 & 0.777 & 16.016 & 0.604 & 0.789 \\
\cline { 2 - 6 } & LG3 & 0.790 & 16.400 & 0.625 & 0.787 \\
\cline { 2 - 6 } & LG4 & 0.760 & 15.526 & 0.577 & 0.802 \\
\hline overall & & & & & 0.958 \\
\hline
\end{tabular}

Table 6. Absolute Fit Indices of the Proposed Model

\begin{tabular}{|c|c|c|c|c|c|c|}
\hline Fit Indices & \multicolumn{6}{|c|}{ Absolute } \\
\hline Name & $\mathrm{X}^{2} / \mathrm{df}$ & GFI & RMSEA & RMR & SRMR & AGFI \\
\hline Value & 3.601 & 0.831 & 0.087 & 0.094 & 0.061 & 0.893 \\
\hline
\end{tabular}

Table 7. Incremental Fit Indices of the Proposed Model

\begin{tabular}{|c|c|c|c|}
\hline Fit Indices & \multicolumn{3}{|c|}{ Incremental } \\
\hline Name & CFI & NNFI & IFI \\
\hline Value & 0.962 & 0.959 & 0.962 \\
\hline
\end{tabular}

Table 8. Parsimony Fit Indices of the Proposed Model

\begin{tabular}{|c|c|c|}
\hline Fit Indices & \multicolumn{2}{|c|}{ Parsimony } \\
\hline Name & PGFI & PNFI \\
\hline Value & 0.641 & 0.873 \\
\hline
\end{tabular}

The model exhibited an overall good fit, with several exceptions. GFI at 0.831 and AGFI at 0.893 were slightly below but close to the recommended level 0.90 . Although the GFI level could be improved by dropping some items, the dropping procedure was stopped by the consideration on the content of the measurement. RMSEA at 0.087 and SRMR at 0.061 were slightly above but close to the recommended level.

The structural model was evaluated by standardized path estimates and t-values. Path coefficients of latent variable refer to direct influence of reason variables to result variables. Absolute $T$ value greater than $1.96(\alpha=0.05)$ means significant level. Parameter Estimates are showed in Table 5. Fifteen among sixteen proposed direct relationship are statistically significant. $\mathrm{H} 1, \mathrm{H} 2, \mathrm{H} 3, \mathrm{H} 4$ and $\mathrm{H} 6$ were supported, the results confirmed the TAM. The result indicates that AT should be a mediate variable to the impact of PEU on SA. H7 was supported, the result indicated that learning activities a company taken will improve user perceived ease of use of ERP system. $\mathrm{H} 8$ was supported, the result indicated that a clear process definition and strict compliance with the process will help employees to understand how the business operates, thus improve their perceived ease of use of the ERP systems. $\mathrm{H} 9$ and $\mathrm{H} 10$ were supported, the results indicated that managerial efforts on change management will improve user perceived use and ease of use of an ERP system. H11 was supported, the result indicated that an adequate change management can help employees understand and comply with the new business process after the implementation of ERP. H12 was supported; the result indicated that change 
management from organizational and business level will help employees to get benefit from training activities. H13 was supported; the result indicated that training could help employees to deal with conflicts created in implementation and adjust individual working process to comply with the ERP business process. H14, H15 and H16 were supported; the results indicated that leadership support is a fundamental factor which will influence change management, business process and symbolic adoption.

Table 9. Parameter Estimates and Hypotheses Test

\begin{tabular}{|c|c|c|c|c|}
\hline \multicolumn{2}{|c|}{ Hypotheses } & Std. loading & T-value & Conclusion \\
\hline H1 & PEU $\rightarrow$ PU & 0.518 & 8.353 & Supported \\
\hline H2 & PEU $\rightarrow$ AT & 0.486 & 6.746 & Supported \\
\hline H3 & PU $\rightarrow$ AT & 0.293 & 4.269 & Supported \\
\hline H4 & AT $\rightarrow$ SA & 0.920 & 16.104 & Supported \\
\hline H5 & PEU $\rightarrow$ SA & -0.095 & -1.502 & \\
\hline H6 & PU $\rightarrow$ SA & 0.149 & 2.704 & Supported \\
\hline H7 & LG $\rightarrow$ PEU & 0.207 & 3.439 & Supported \\
\hline H8 & BP $\rightarrow$ PEU & 0.268 & 3.059 & Supported \\
\hline H9 & CM $\rightarrow$ PU & 0.354 & 6.176 & Supported \\
\hline H10 & CM $\rightarrow$ PEU & 0.272 & 3.167 & Supported \\
\hline H11 & CM $\rightarrow$ BP & 0.276 & 3.233 & Supported \\
\hline H12 & CM $\rightarrow$ TR & 0.685 & 10.268 & Supported \\
\hline H13 & TR $\rightarrow$ BP & 0.213 & 3.353 & Supported \\
\hline H14 & LD $\rightarrow$ CM & 0.730 & 12.864 & Supported \\
\hline H15 & LD $\rightarrow$ BP & 0.438 & 5.928 & Supported \\
\hline H16 & LD $\rightarrow$ SA & 0.110 & 2.589 & Supported \\
\hline
\end{tabular}

\section{CONCLUSIONS}

The critical success factors have been identified and tested in literatures for years, but in which way these critical success factors influence implementation of ERP system is still unclear. This research tested the impacts of some critical success factors on the user perceived use and ease of use based on TAM. The results confirmed the impacts of change management, business process and learning ability on perceived use and ease of use. Change management ability will contribute to the definition and clarification of business process. Good change management could provide suitable and enough training to employees, helping them to understand and comply with the new business process. Leadership champion of ERP plays a fundamental part in the support of change management, business process and the overall symbolic adoption of ERP system.

In general, the results imply that the implementation environment such as leadership support, change management, business process are critical to user perceived use and ease of use of an ERP system, they influence the adoption then the implementation effectiveness of an ERP system. To pursue a successful 
implementation, it is vital to create a suitable atmosphere around the enterprise. The more useful and easier to use an ERP system, the more value the system will produce.

\section{REFERENCES}

1. M. Fishbein and I. Ajzen, Belief, Attitude, Intention, and Behavior: an Introduction to Theory and Research (Addison-Wesley: Reading, MA, 1975).

2. I. Ajzen and M. Fishbein, Understanding Attitudes and Predicting Social Behavior (Prentice-Hall: Englewood Cliffs, NJ 1980).

3. I. Ajzen, From intentions to actions: A Theory of Planned Behavior, in Action-control: From cognition to behavior, eds. J. Kuhl and J. Beckman (Springer: Heidelberg, 1985), pp.11-39.

4. I. Ajzen, The Theory of Planned Behavior, Organizational Behavior and Human Decision Processes. Volume 50, Number 2, pp.179-211, (1991).

5. F.D. Davis, Perceived Usefulness, Perceived Ease of Use and User Acceptance of Information Technology, MIS Quarterly. Volume 13, Number 3, pp.319-340, (1989).

6. F.D. Davis, R.P. Bagozzi, and P.R. Warshaw, User Acceptance of Computer Technology: A Comparison of Two Theoretical Models, Management Science. Volume 35, Number 8, pp.982-1003, (1989).

7. E. Karahanna, D.W. Straub, and N.L. Chervany, Information Technology Adoption across Time: A Cross-sectional Comparison of Pre-adoption and Post-adoption Beliefs, MIS Quarterly. Volume 23, Number 2, pp.183-213, (1999).

8. P. Rawstorne, R. Jayasuriya, and P. Caputi, An Integrative Model of Information Systems Use in Mandatory Environments, in Proc. of the Nineteenth International Conference on Information Systems, eds. J. I. DeGross, R. Hirschheim, and M. Newman (Association for Information Systems: Atlanta, GA, 1998), pp.325-330.

9. L. Tornatzky and K. Klein, Innovation Characteristics and Innovation Adoption Implementation: a Meta Analysis of Findings, IEEE Transactions on Engineering Management. Volume 29, Number 1, pp.28-45, (1982).

10. C. Holland and B. Light, A Framework for Understanding Success and Failure in Enterprise Resource Planning System Implementation, in Second-wave Enterprise Resource Planning Systems, eds. G. Shanks, P.B. Seddon, and L.P. Willcocks (Cambridge University Press: Edinburgh, 1999), pp.180-195.

11. F.F. Nah, J.L. Lau, and J. Kuang, Critical Factors for Successful Implementation of Enterprise Systems, Business Process Management Journal. Volume 7, Number 3, pp.285-296, (2001).

12. T.M. Somers and K.G. Nelson, The Impact of Critical Success Factors across the Stages of Enterprise Resource Planning Implementations, in Proc. of the 34th Annual Hawaii International Conference on System Sciences (IEEE Computer Society: Washington, DC, $2001)$, pp.8016.

13. H. Akkermans and K. Helden, Vicious and Virtuous Cycles in ERP Implementation: a Case Study of Interrelations between Critical Success Factors, European Journal of Information Systems. Volume 11, Number 1, pp.35-46, (2002).

14. C.F. Ho, W.H. Wu, and Y.M. Tai, Strategies for the Adaptation of ERP Systems, Industrial Management + Data Systems. Volume 104, Number 3, pp.234-251, (2004).

15. P. Kraemmergaard and J. Rose, Managerial Competences for ERP Journeys, Information Systems Frontiers. Volume 4, Number 2, pp.199-211, (2002).

16. J. Magnusson and A. Nilsson, A Conceptual Framework for Forecasting ERP Implementation Success: A first step towards the creation of an implementation support tool, in Proceedings of the 6th International Conference on Enterprise Information 
Systems, eds. I. Seruca, J. Filipe, S. Hammoudi, and J. Cordeiro (Universidade Portucalense: Porto, Portugal, 2004), pp.447-453.

17. F.F. Nah, K.M. Zuckweiler, and J.L. Lau, ERP Implementation: Chief Information Officers' Perceptions of Critical Success Factors, International Journal of HumanComputer Interaction. Volume 16, Number 1, pp.5-22, (2003).

18. F.F. Nah and S. Delgado, Critical Success Factors for Enterprise Resource Planning Implementation and Upgrade, The Journal of Computer Information Systems. Volume 46, Number 5, pp.99-113, (2006).

19. P. Ifinedo and N. Nahar, ERP Systems Success: an Empirical Analysis of How Two Organizational Stakeholder Groups Prioritize and Evaluate Relevant Measures, Enterprise Information Systems. Volume 1, Number 1, pp.25-48, (2007).

20. D.L. Olson and F. Zhao, CIOs' Perspectives of Critical Success Factors in ERP Upgrade Projects, Enterprise Information Systems. Volume 1, Number 1, pp.129-138, (2007).

21. J.K. Stratman and A.V. Roth, Enterprise Resource Planning (ERP) Competence Constructs: Two-Stage Multi-Item Scale Development and Validation, Decision Sciences. Volume 33, Number 4, pp.601-628, (2002).

22. S. August-Wilhelm, and F. Habermann, Making ERP a Success, Communications of the $A C M$. Volume 43, Number 4, pp.57-61, (2000).

23. A.V. Roth, J. Julian, and M.K. Malholtra, Assessing Customer Value for Reengineering: Narcissistic Practices and Parameters from the Next Generation, in Business process change: Reengineering Concepts, Methods, and Technologies, eds. W. Kettinger and V. Grover (Idea Group Publishing: Harrisburg, PA, 1995), pp.453-474.

24. D. Elizur and L. Guttman, The Structure of Attitudes toward Work and Technological Change within an Organization, Administrative Science Quarterly. Volume 21, Number 4, pp.611-623, (1976).

25. K. Kwahk, ERP Acceptance: Organizational Change Perspective, in: Proceedings of the 39th Annual Hawaii International Conference on System Sciences (IEEE Computer Society: Washington, DC, 2006), pp.1726.

26. C.S. Yu, Causes Influencing the Effectiveness of the Post-implementation ERP System, Industrial Management + Data Systems. Volume 105, Number 1, pp.115-132, (2005).

27. M.A. Mashari, A.A. Mudimigh, and M. Zairi, Enterprise Resource Planning: A Taxonomy of Critical Factors, European Journal of Operational Research. Volume 146, Number 2, pp.352-364, (2003).

28. G.A. Churchill, A Paradigm for Developing Better Measures of Marketing Constructs, Journal of Marketing Research. Volume 16, Number 3, pp.64-73, (1979).

29. E.J. Pedhazur and L.P. Schmelkin, Measurement, Design, and Analysis: An Integrated Approach (Lawrence Erlbaum Associates: Hillsdale, NJ, 1991).

30. K.A. Bollen, Overall Fit in Covariance Structural Models: Two Types of Sample Size Effects, Psychological Bulletin. Volume 107, Number 2, pp.256-259, (1990). 